\title{
TIME TO RETURN OF GASTRIC MYOELECTRICAL ACTIVITY AFTER BOLUS DOSES OF SHORT-ACTING OPIOIODS.
}

\section{Conclusions}

Gastric activity was affected by fentanyl and alfentanil. The gastric effect was shortacting as a normal EGG-activity was observed in all subjects within one hour. In the doses given, the time until return of normal gastric activity seems to follow the pharmacokinetic profile of the opioids.

\section{Background}

Opioids affects gastric motility and studies have shown that the normal slow-wave peristaltic activity of 3 cycles per minute (cpm) gets impaired (1). The interference with gastric motility might cause nausea, vomiting and prolonged time until postoperative beginning of oral intake. The aim of the study was to investigate time to the return of normal gastric activity after administration of short-acting opioids used in the perioperative setting.

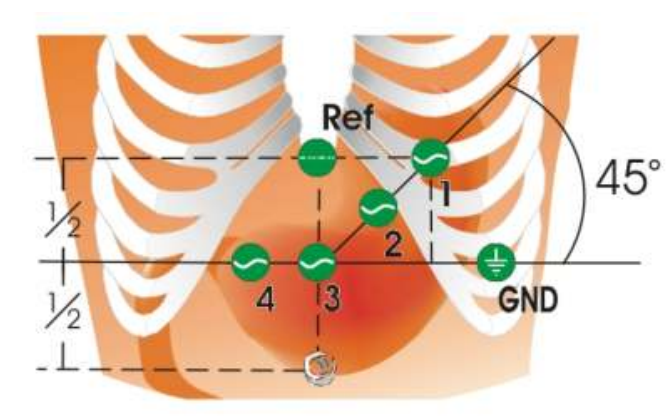

\section{Figure 1}

Electrogastrography(EGG)

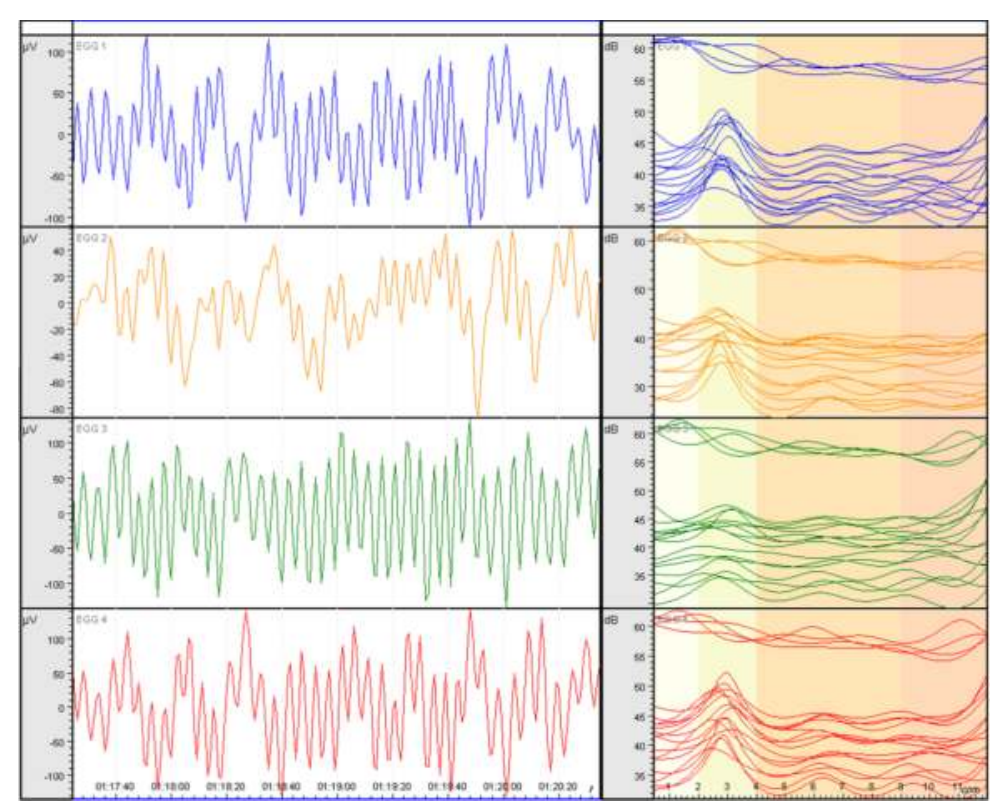

\section{Materials and Methods}

20 voluntary healthy subjects were included in this prospective observational study. Subjects were examined with electrogastrography (EGG), a non-invasive method to study gastric myoelectric activity. After 20 minutes of baseline registration, fentanyl $1 \mu \mathrm{g} / \mathrm{kg}(\mathrm{n}=10)$ or alfentanil $5 \mu \mathrm{g} / \mathrm{kg}(\mathrm{n}=10)$ was given as an intravenous bolus dose and the EGG-registration continued until return of normal activity. Dominant EGG frequency was obtained in overlapping 10-minute intervals and time until return of normal (baseline) activity was identified.

\section{Results}

The mean dominant frequency before administration of opioids were regarded as normal with $2,93 \mathrm{cpm}( \pm 0,19)$ in the fentanyl group and 2,98 cpm $( \pm 0,21)$ in the alfentanil group. 10 minutes after the administration of opioid, there was a significant change in both series in EGG-activity with great variations in the individual responses.

In most subjects, the main effect was an uncoordinated activity without any detectable dominant frequency. The EGG was not affected at all in 1 subject in the fentanyl group and 2 subjects in the alfentanil group.

The median time until return of normal EGG-activity was 40 min $(15-60)$ in the fentanyl group and 20 min (10-45) in the alfentanil group.

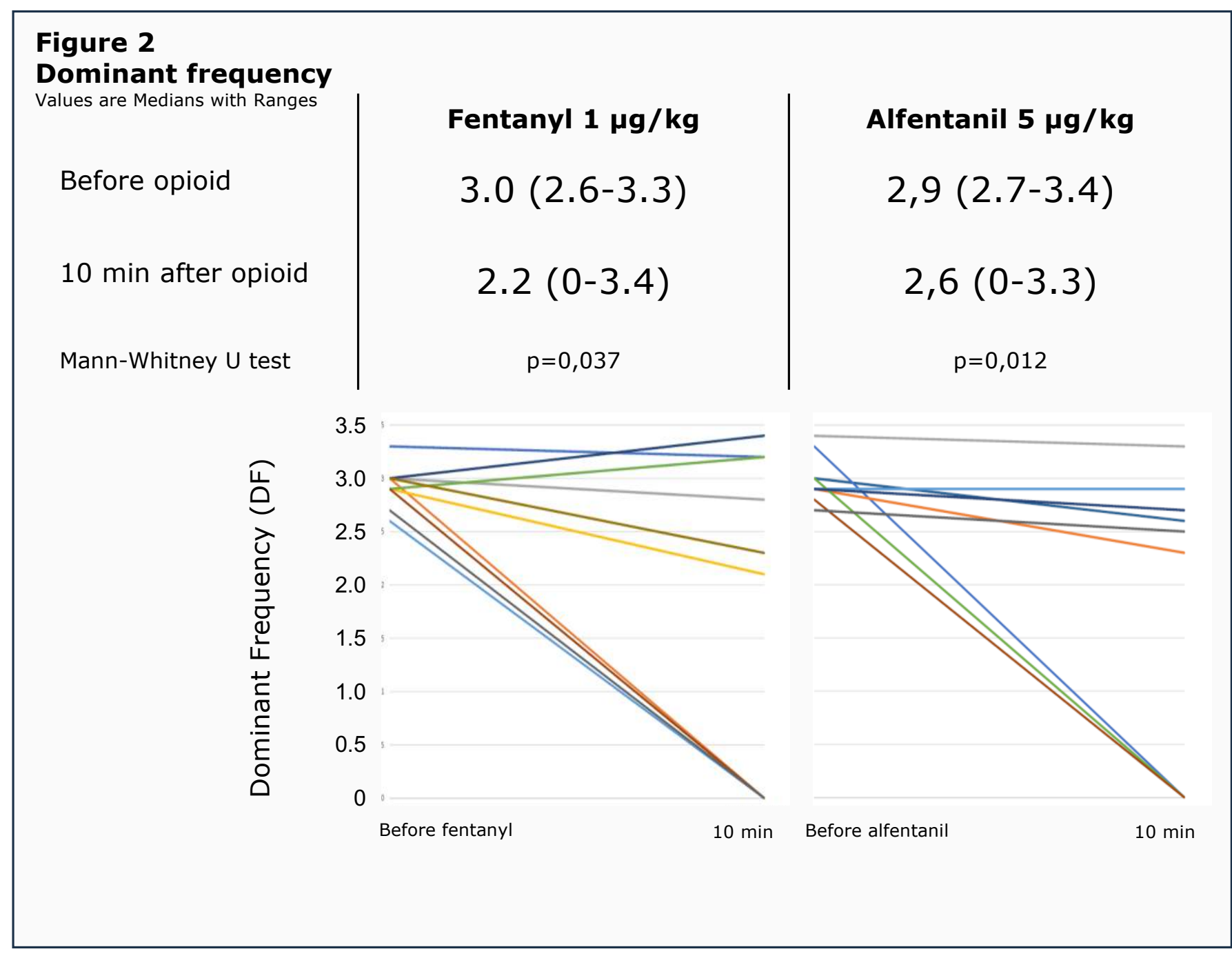

References:

1. Wallden et al 2008 Acta Anesth Scand 52(5) 708-15

\section{UMEÅ UNIVERSITY}

